Tema: Solidificação / Lingotamento

\title{
INTERAÇÃO DE METAL E ESCÓRIA DE TOPO DENTRO DO MOLDE DE LINGOTAMENTO CONTÍNUO*
}

\author{
José Dimas Arruda \\ Alexandre Leopoldo Pereira ${ }^{2}$ \\ Ana Elizabeth Teixeira de Souza ${ }^{2}$ \\ Gabriel Romeu Trindade dos Santos ${ }^{2}$ \\ Carlos Antônio da Silva ${ }^{3}$ \\ Itavahn Alves da Silva ${ }^{3}$ \\ Varadajan Seshadri ${ }^{4}$
}

\section{Resumo}

O conhecimento do campo de fluxo dentro do molde pode oferecer uma oportunidade de melhorar a limpidez interna do produto final. A técnica PIV foi empregada para avaliar a distribuição de velocidade longitudinal ao longo de uma ampla seção variando da válvula submersa até a face estreita de um molde de lingotamento de placas, bem como a distribuição de velocidade transversal correspondente. Estas informações podem ser utilizadas para avaliar o grau de turbulência interfacial.

Palavras-chave: Lingotamento contínuo; Molde; Escória; Interação.

\section{TOP SLAG METAL INTERACTION INSIDE A CONTINUOUS CASTING MOLD}

\begin{abstract}
The knowledge of the flow field inside the mold can offer an opportunity to improve operations and as a result to achieve better inclusion control. PIV technique has been employed to assess the longitudinal velocity distribution along a wide section ranging from Submerged Entry Nozzle to narrow face of the mold as well as the corresponding transversal velocity distribution. This can be used to evaluate the degree of interfacial turbulence.
\end{abstract}

Keywords: Continuous casting; Mold; Slag; Steel; Interaction.

1 Engenheiro Metalúrgico, Mestrando em Engenharia de Materiais, Redemat, Universidade Federal de Ouro Preto, Ouro Preto, Minas Gerais, Brasil.

Graduando em Metalurgia, Escola de Minas, Ouro Preto, Minas Gerais, Brasil.

3 Engenheiro Metalúrgico, Ph.D., Professor, Universidade Federal de Ouro Preto, Escola de Minas, Ouro Preto, Minas Gerais, Brasil.

4 Engenheiro Metalúrgico, Dr. Ing., Professo Emérito, Universidade Federal de Minas Gerais (UFMG), Belo Horizonte, Minas Gerais, Brasil.

* Contribuição técnica ao 45 Seminário de Aciaria - Internacional, 25 a 28 de maio de 2014, Porto Alegre, RS, Brasil. 


\section{INTRODUÇÃO}

A região do molde de lingotamento contínuo é a última oportunidade de preservação e melhoria do produto lingotado. O fluxo de aço descarregado no molde induz correntes de circulação, gerando instabilidades na região do menisco, as quais são responsáveis pelo desenvolvimento de vórtices nas imediações da SEN bem como flutuações e cisalhamento na interface poça de aço-escória, Figura 1. Estas flutuações na região do menisco e o campo de velocidades na poça de aço afetam a taxa de fusão e entranhamento do fluxante; a velocidade de crescimento da pele e o aprisionamento de escória, pó fluxante e bolhas. Tanto a velocidade do fluxo como a flutuação de nível do menisco é aumentada com o aumento da velocidade de lingotamento, redução da profundidade e diminuição do ângulo das portas da SEN, além do aumento da vazão de argônio no molde, as quais provocam o aumento da taxa de entranhamento de pó fluxante. A velocidade de lingotamento exerce maior efeito dentre estes parâmetros [1-5].
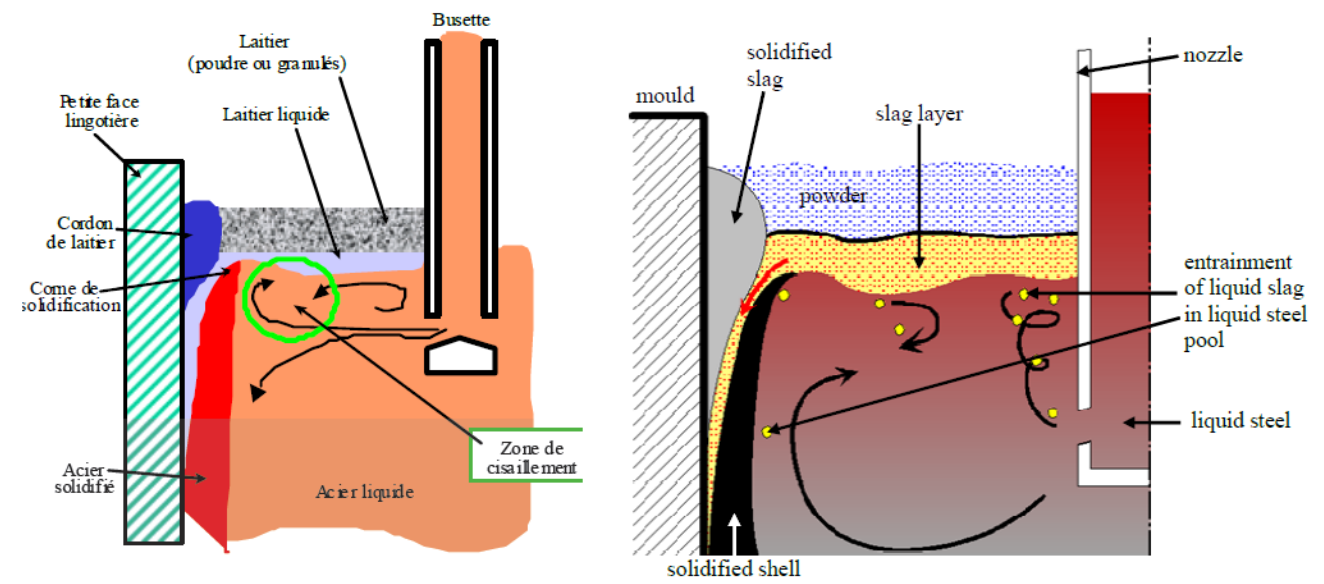

Figura 1. Fenômenos ocorrentes no interior do molde de lingotamento contínuo [5].

O entranhamento de escória no molde é a principal fonte de macroinclusões, o que justifica a necessidade de estabilização do nível de flutuações na região do menisco. Os mecanismos de entranhamento do fluxante na poça de aço incluem o desenvolvimento de vórtices e sucção na válvula submersa devido à distribuição assimétrica do fluxo e ao fluxo excessivo impingente contra a superfície da poça de aço no menisco, flutuações de nível de aço no molde; os efeitos do trem de bolhas de argônio e a instabilidade na interface poça de aço-escória, na região do menisco, Figura 2. O entranhamento do pó fluxante e escória na poça de aço deterioram a limpidez do produto lingotado.

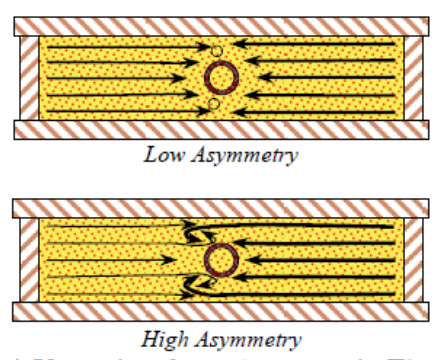

a) Vortexing from Asymmetric Flow

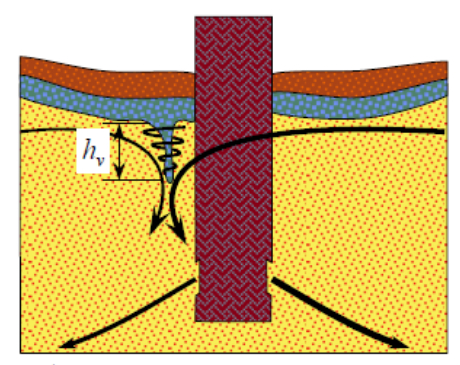

b) Subcritical Vortex Formation

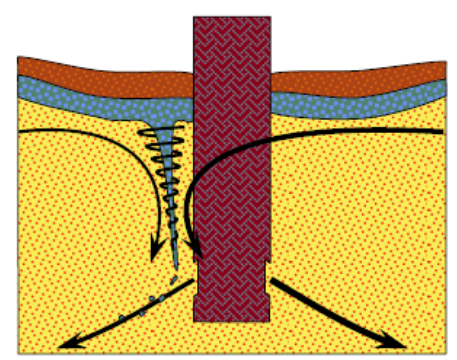

c) Entrainment from Deep Vortex

Figura 2. Entranhamento de escória devido à formação de vórtices de von Karman nas imediações da SEN [4].

* Contribuição técnica ao $45^{\circ}$ Seminário de Aciaria - Internacional, 25 a 28 de maio de 2014, Porto Alegre, RS, Brasil. 


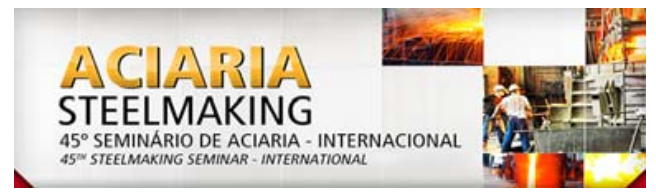

Igualmente, a espumação da escória, na região do menisco, devido ao fluxo de argônio, incentiva a aderência e arraste de escória sobre a superfície da SEN, Figura 3. Com isto, o jato de aço descarregado no molde pode causar o aprisionamento de inclusões de escória na poça de aço.

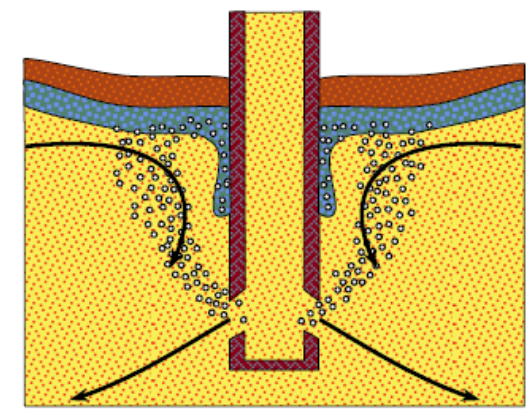

a) Foam Formation

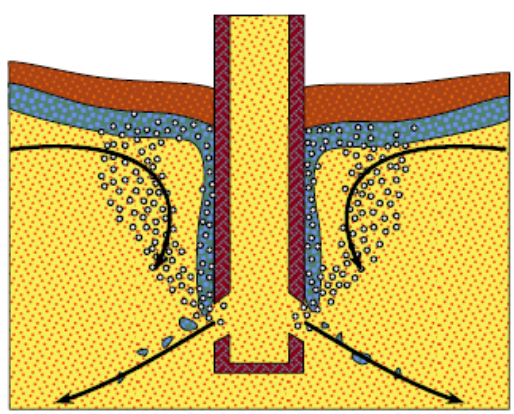

b) Entrainment Due to Slag Foam

Figura 3. Espumação da escória no menisco do molde de LC [4].

Estas interações entre o aço e a escória, na região do menisco, são estabelecidas pelo campo de velocidades. Com isto, o mapeamento deste campo em função de condições operacionais de lingotamento fazem-se importantes para o controle da qualidade do produto lingotado.

\section{MATERIAIS E MÉTODOS}

Um modelo físico em acrílico, Figura 4a foi utilizado para determinação do campo de velocidades na região superficial no molde de lingotamento contínuo de placas. Os adimensionais de Froude e Weber foram utilizados como critério de similaridade.

O mapa de velocidades foi determinado por meio da técnica PIV, Figura 4b. Utilizou-se um aparelho DANTEC - 2D, o qual compõe-se de sistema laser Dual power - 65/15 400mJ, com duração de pulsos de 4ns, faixa de comprimento de onda entre $1064 \mathrm{~nm}$ e $532 \mathrm{~nm}$, além de uma câmera CCD Flow-Sense 2ME. A análise de imagens for realizada via software Dynamics Studio - Dantec. Para todas as condições experimentais, foram adquiridas cerca de 300 imagens com intervalo de tempo de $3000 \mu$ s e frequência de captura $10 \mathrm{~Hz}$. Esta técnica foi utilizada tanto para o mapeamento longitudinal como para o transversal, como detalhado a seguir.
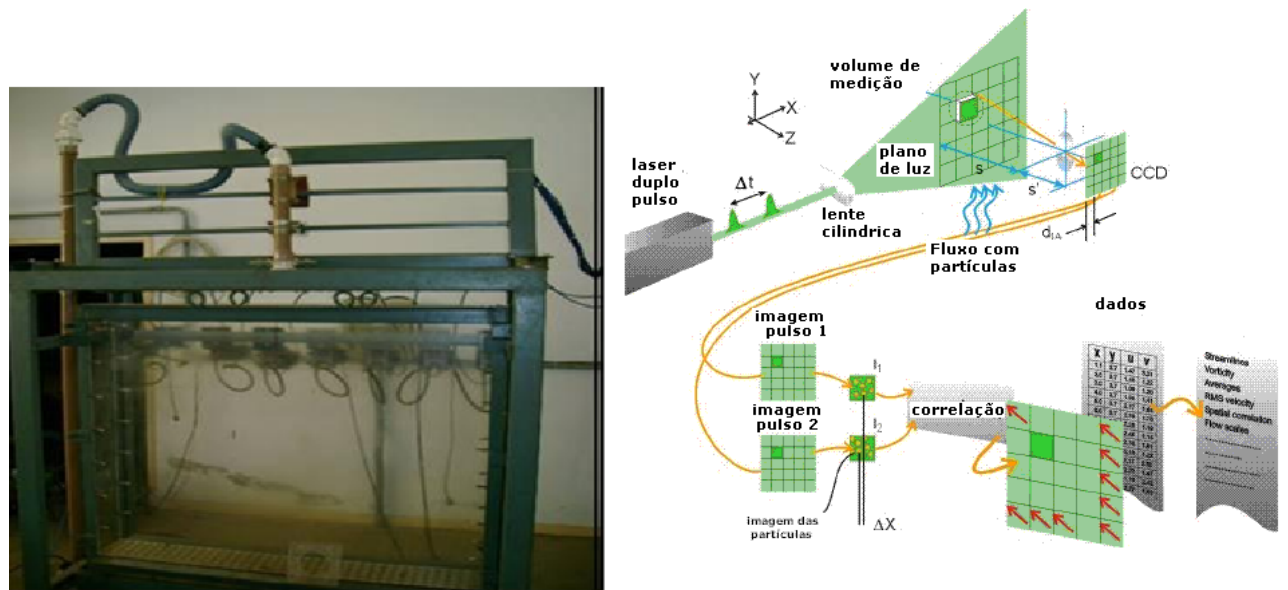

Figura 4. Modelo físico do molde de lingotamento contínuo (DEMET/EM/UFOP).

* Contribuição técnica ao 45 Seminário de Aciaria - Internacional, 25 a 28 de maio de 2014, Porto Alegre, RS, Brasil. 


\section{RESULTADO}

A Figura 5 apresenta as regiões de medição de velocidades, localizadas em um plano vertical, paralelo à face larga do molde, e cortando o centro da SEN. A área de abrangência da câmera CCD, do sistema PIV, corresponde a um quadrado de aproximadamente $10 \mathrm{~cm} \times 10 \mathrm{~cm}$, o que justifica a divisão empregada. Os mapas vetoriais gerados representam o perfil de velocidades em função da distância vertical a partir do topo da camada de aço líquido em direção ao seu interior. As linhas verticais estão identificadas na Figura 5, pela distância a partir da SEN. Para obter uma caracterização completa do menisco, o molde foi dividido em cinco regiões; a partir da válvula submersa até o encontro da face estreita do molde; cada região com três intervalos, distanciados de três centímetros, havendo maior abrangência da câmera cada região subdividida em três linhas verticais para melhor compreensão do fluxo.

Através dos mapas vetoriais foi possível observar a distribuição do fluxo na forma de um duplo rolo, o que foi comprovado pela utilização de uma rede com fios de lã, posicionada no plano médio do molde, Figura 6. Este comportamento é observado para todas as vazões e profundidades de imersão da SEN.

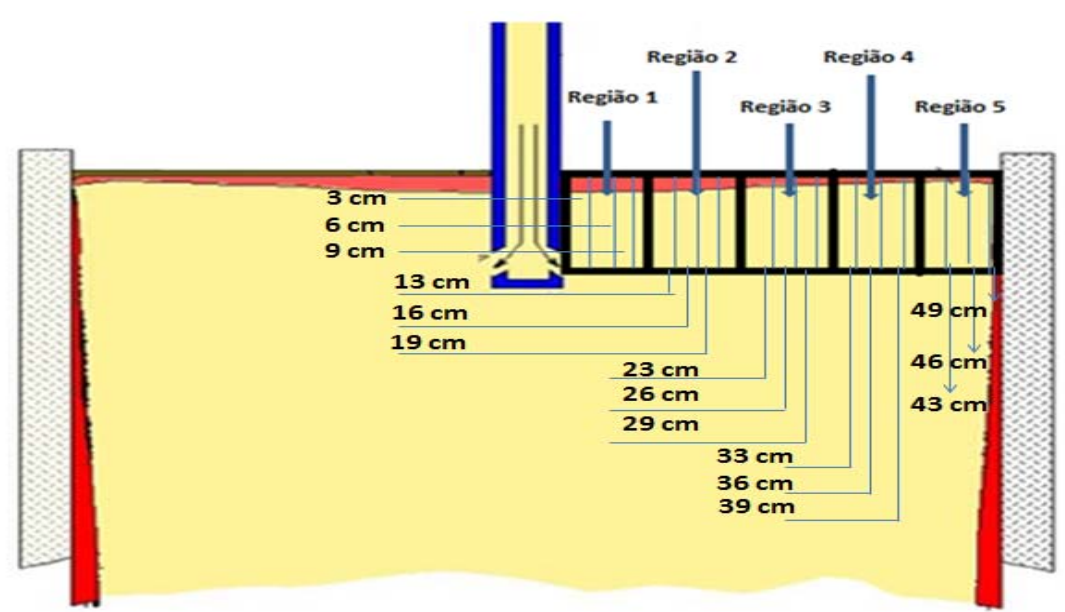

Figura 5. Regiões de análise de velocidade no molde de Lingotamento Contínuo mostrando as distâncias verticais analisadas em cada região.

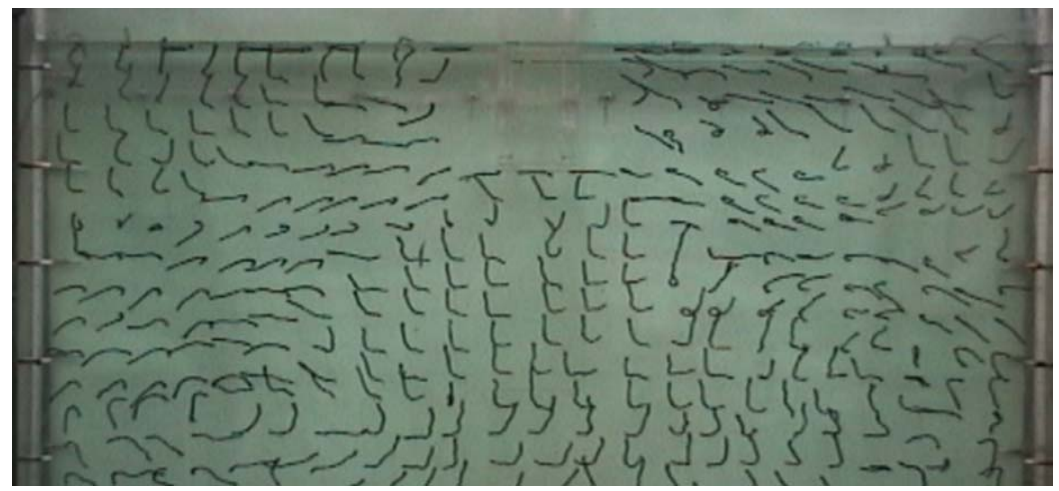

Figura 6. Perfil de velocidade no molde de Lingotamento Contínuo, caracterizado pelo movimento de fios de lã.

As Figuras 7, 8 e 9 mostram a variação do módulo de velocidade com a distância vertical a partir do topo da poça de aço, para diferentes velocidades de lingotamento, com profundidade de imersão da SEN de $110 \mathrm{~cm}$, com e sem a presença de escória.

* Contribuição técnica ao $45^{\circ}$ Seminário de Aciaria - Internacional, 25 a 28 de maio de 2014, Porto Alegre, RS, Brasil. 


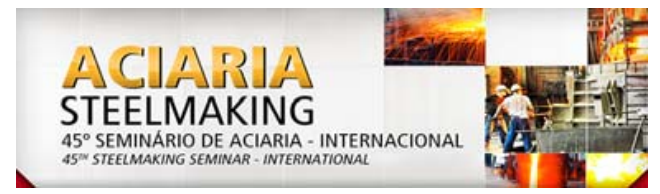

Analisando a Figura 7, observa-se que ao longo do molde a velocidade do fluxo apresenta uma tendencia de crescimento do topo do reator para locais com maior profundidade, notadamente em regiões mais próximas da SEN. Na região 2, mais próxima à válvula submersa, a velocidade do fluxo é maior que nas outras regiões, onde há uma maior distância da SEN, região 3 e 4, o que provavelmente se deve à inversão de fluxo junto à válvula, característica do duplo rolo. A região 3, intermediária entre SEN e face estreita, apresenta possui um fluxo com baixa variação no módulo de velocidade, indicativo de fluxo completamente desenvolvido nesta região, porção superior do " loop" de recirculação. Na região 4, próxima à face estreita, as velocidades são menores e não se alteram de modo signifcativo com o aumento da vazão, provavelmente porque as regiões de circulação mais intensa do "loop" não se estendem a posições muito próximas da face estreita. Esta tendência é determinada por uma combinação de vazão e largura do molde, principalmente. Um possível efeito de frenagem do fluido, em função da presença de uma camada de escória, é sensível apenas na região intermediária.
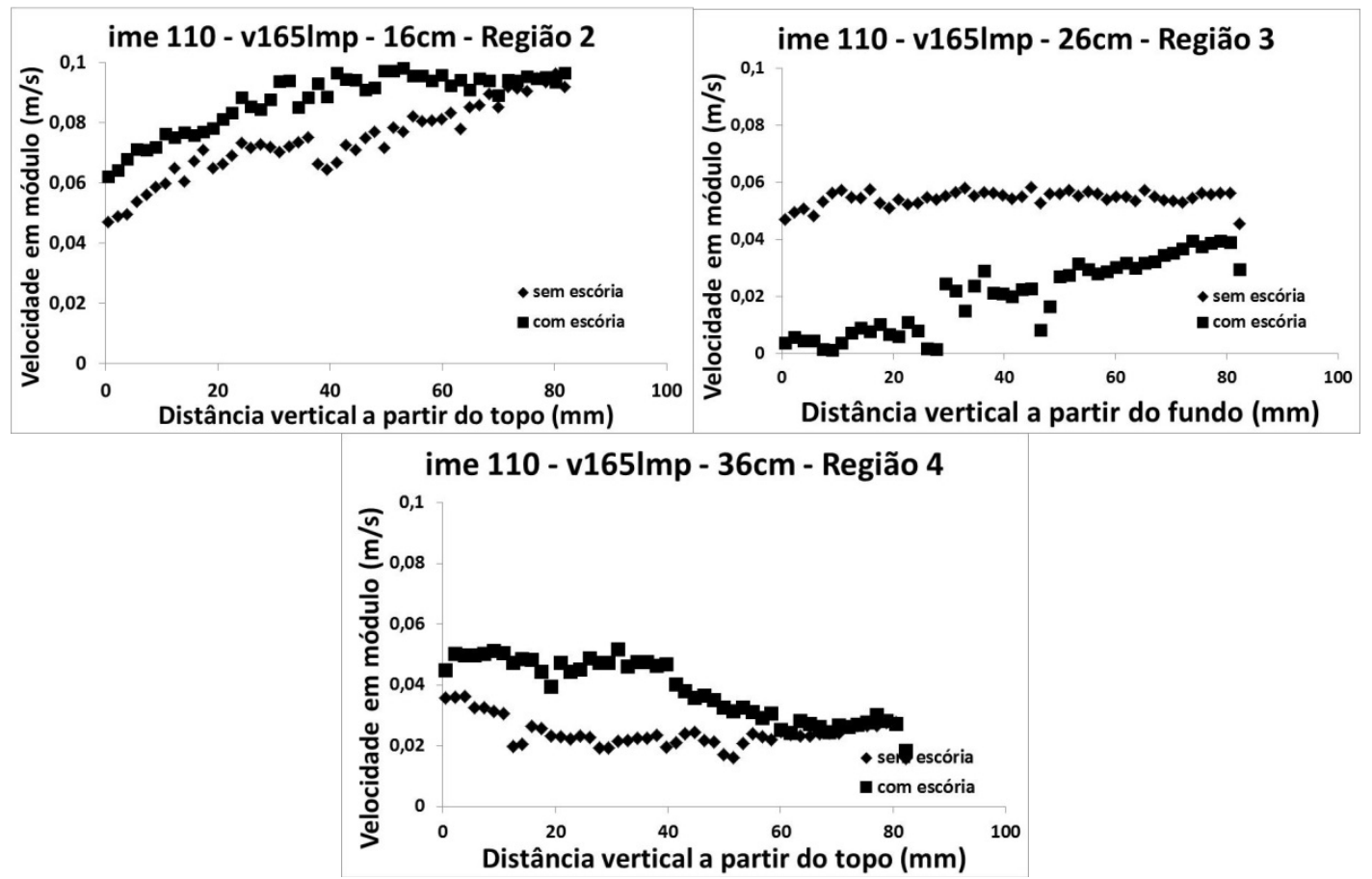

Figura 7. Módulo de velocidade no menisco com a distância vertical e horizontal para diferentes distâncias a partir da SEN, nos casos sem e com escória de topo.

As Figuras 8 e 9 mostram que o aumento de vazão acarreta um aumento de velocidade do fluxo. A velocidade permanece maior na região mais próxima da SEN, onde estas aumentam do topo em direção a regiões mais profundas. Em regiões mais próximas à face estreita, observam-se menores velocidades de fluxos, em ambas as situações com e sem a presença de escória. Assim como no caso de baixa vazão de fluxo, não se pode ter uma conclusão da influência da presença de escória no mesmo, em todas vazões estudadas.

* Contribuição técnica ao 45 Seminário de Aciaria - Internacional, 25 a 28 de maio de 2014, Porto Alegre, RS, Brasil. 

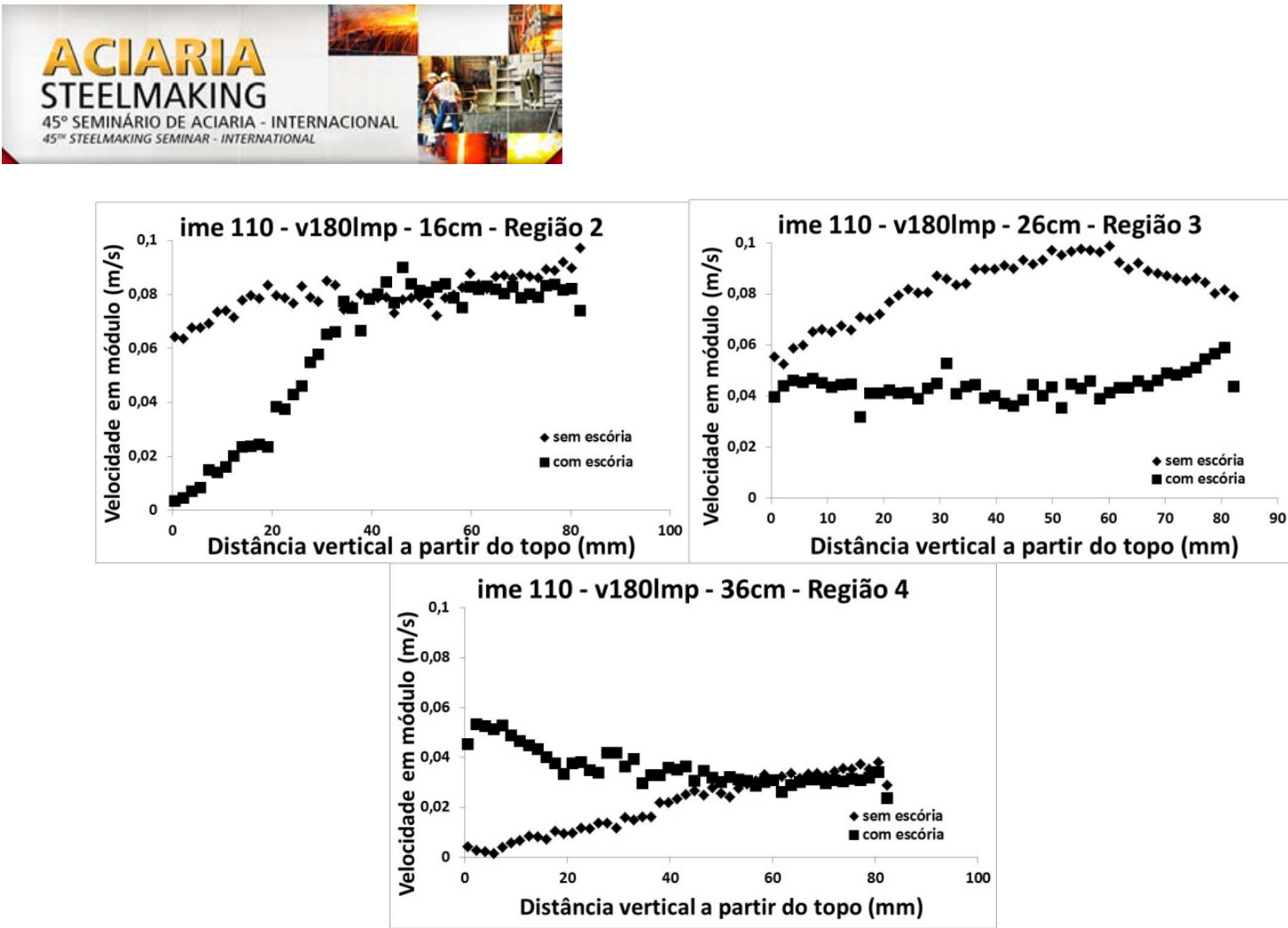

Figura 8. Módulo de velocidade no menisco com a distância vertical e horizontal para diferentes distâncias a partir da SEN, nos casos sem e com escória de topo.
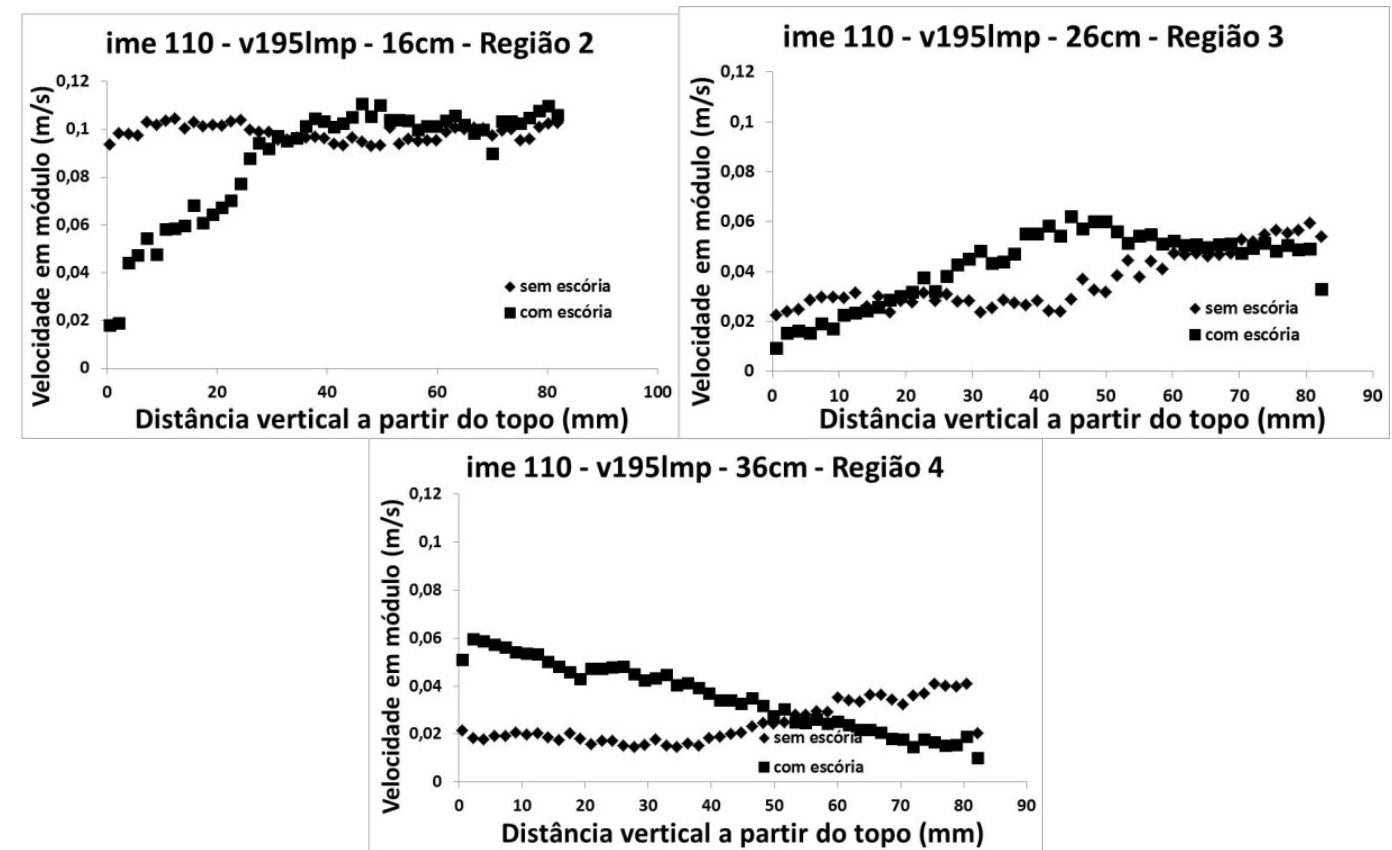

Figura 9. Módulo de velocidade no menisco com a distância vertical e horizontal para diferentes distâncias a partir da SEN, nos casos sem e com escória de topo.

Analisou-se também a influência da imersão da válvula submersa, na velocidade do fluxo de lingotamento contínuo. A Figura 10 confirma que, na vazão de $165 \mathrm{lpm}$, as velocidades são maiores próximo a SEN e que a variação de imersão é significante apenas nas regiões 2 e 3, não afetando as regiões extremas do molde. As alterações são sentidas na região intermediária entre SEN e face estreita, sendo que maiores velocidades ocorrem em maiores imersões da válvula. Nas regiões próximas a face estreita, região 4 e 5, a velocidade de fluxo é baixa em ambas as imersões, efeito da frenagem do fluxo pela parede do molde e da pouca abrangência do "loop" de circulação.

* Contribuição técnica ao 450 Seminário de Aciaria - Internacional, 25 a 28 de maio de 2014, Porto Alegre, RS, Brasil. 

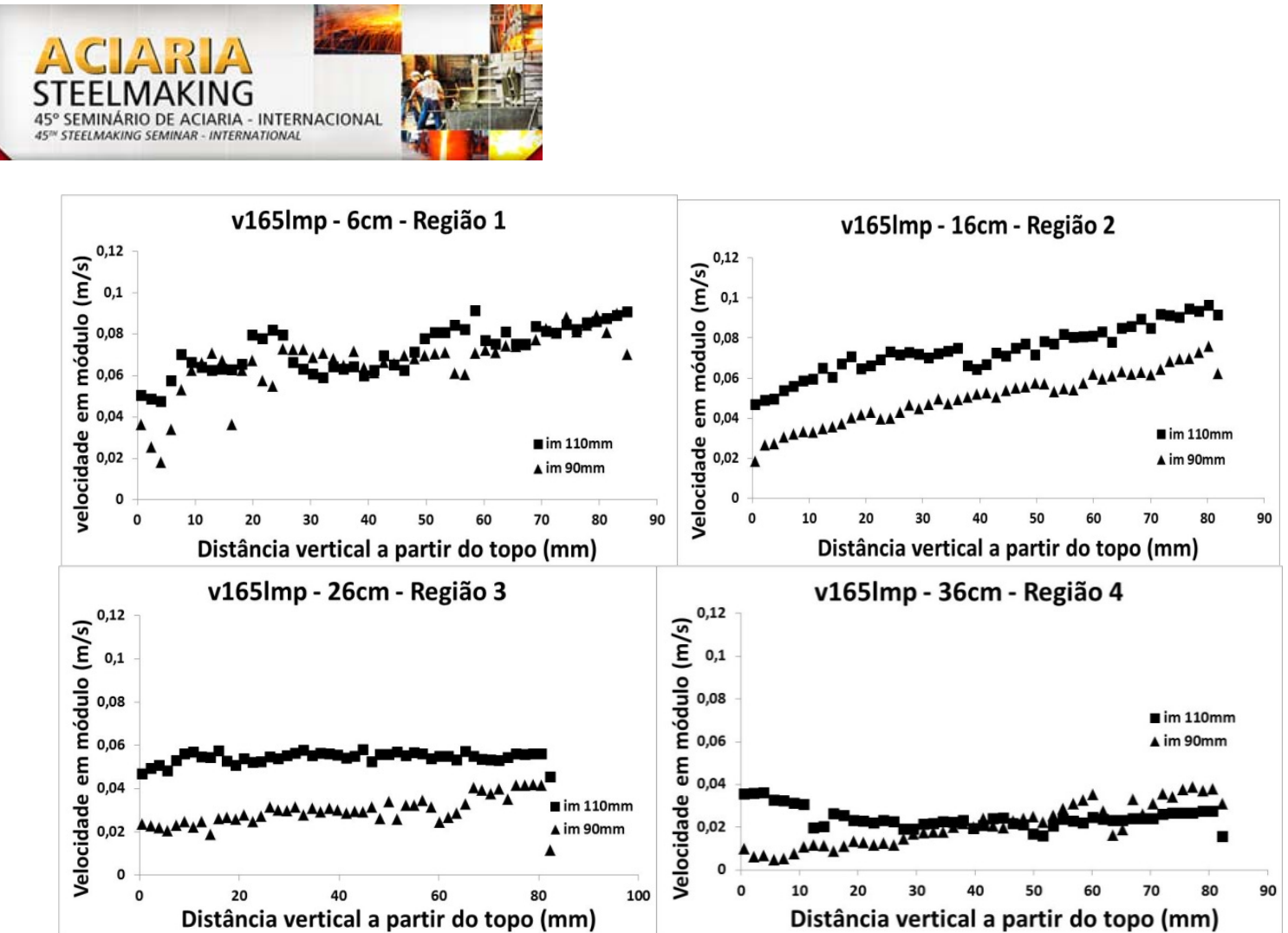

v165Imp - 46cm - Região 5

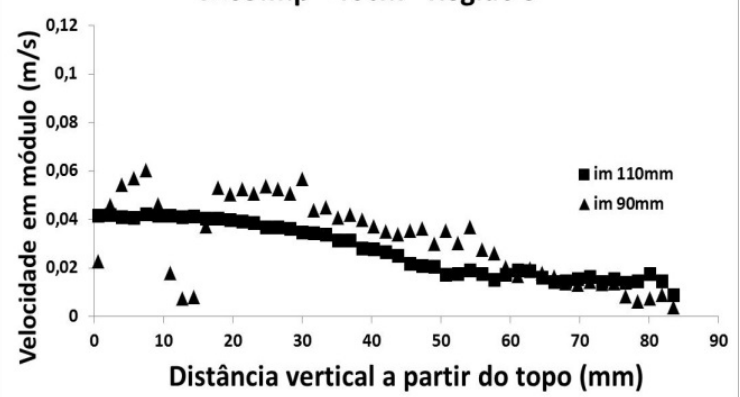

Figura 10. Módulo de velocidade no menisco com a distância vertical e horizontal para diferentes distâncias a partir da SEN, em duas imersões diferentes.

Foram também realizadas medições de velocidade da vista superior do molde, em plano horizontal distante de cerca de $1 \mathrm{~cm}$ da interface líquido - Como mostra a Figura 11, a região de observação compreende 7 regiões, entre a válvula submersa e a face estreita do molde. Os testes foram realizados para imersão de $100 \mathrm{~mm}$ da válvula submersa, na ausência de escória e para diferentes vazões pela SEN.

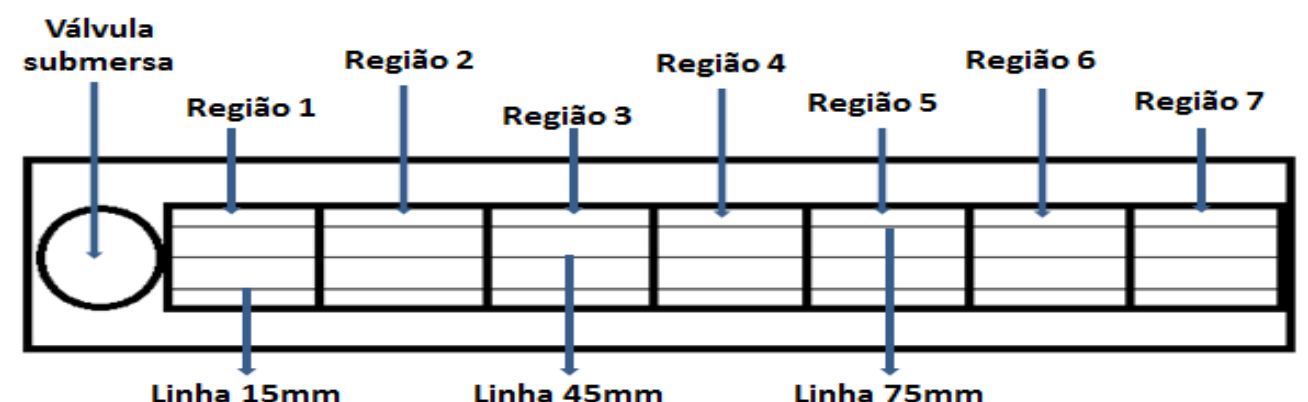

Figura 11. Posições de velocidade analisadas no molde de Lingotamento Contínuo na vista de topo.

A Figura 12 mostra o perfil de velocidade do fluxo no topo do molde, e, como indicado, na região central entre as faces largas. Nota-se que, em geral as curvas se superpõem, indicando não haver variação significativa de velocidade no entorno da linha central (paralela à face larga, que passa pelo centro da SEN). Esta

* Contribuição técnica ao 450 Seminário de Aciaria - Internacional, 25 a 28 de maio de 2014, Porto Alegre, RS, Brasil. 
caracterísitica é indicativa de fluxo duplo rolo, simétrico. Na região 7 , devido a proximidade com a face estreita e pequena abrangência do "loop" de circulação se nota uma diminuição do fluxo, que pode ser causado pelo efeito de frenagem da parede e inversão do fluxo. As curvas em cada gráfico mostram que a vazão pela SEN não interfere de forma perceptível no fluxo sub-superficial no molde, exceto na região intermediária, região 4, posição superior do "loop" de circulação.
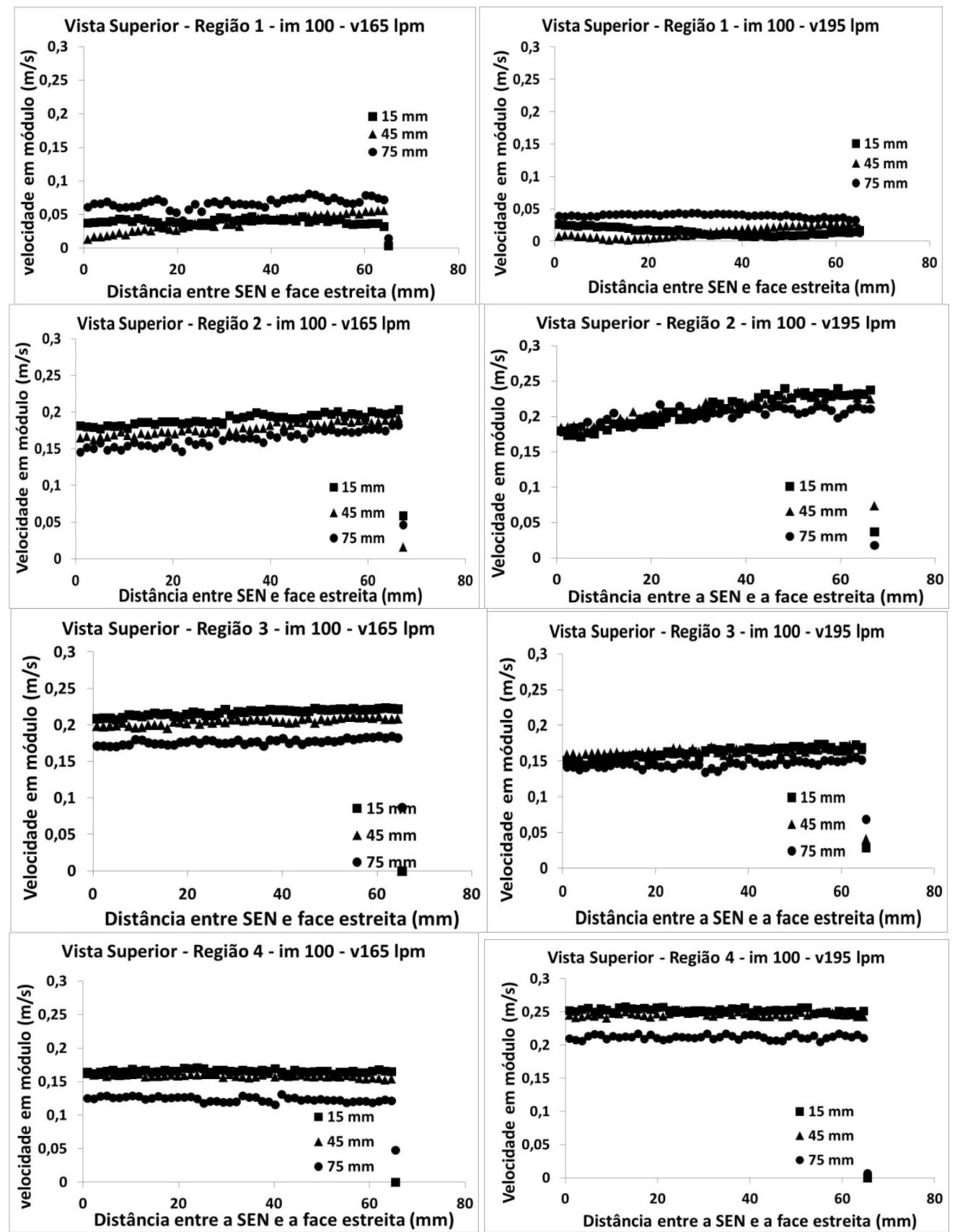

Figura 12. Análise de velocidade média do fluxo a partir da distância vertical a partir do topo observada na vista superior do topo do molde, nas regiões próximas à SEM.

* Contribuição técnica ao $45^{\circ}$ Seminário de Aciaria - Internacional, 25 a 28 de maio de 2014, Porto Alegre, RS, Brasil. 

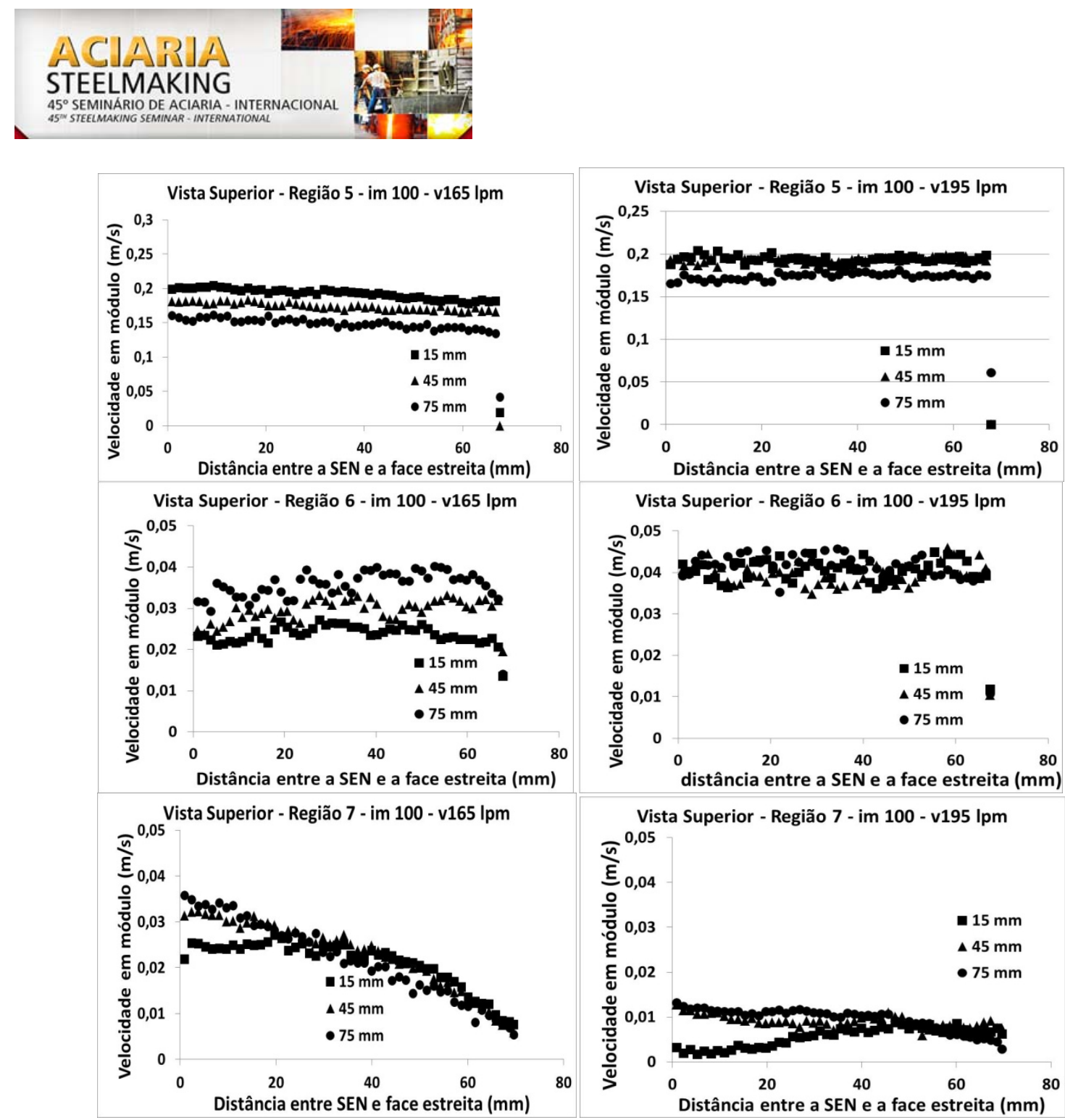

Figura 13. Análise de velocidade média do fluxo a partir da distância vertical a partir do topo observada na vista superior do topo do molde, nas regiões próximas à face estreita.

Os resultados obtidos mostram que a região de maior turbulência é formada nas imediações das portas da SEN. A distribuição assimétrica de velocidades, no topo do molde, é responsável direta no desenvolvimento de vórtices, junto à parede da SEN. Hibbeler \& Thomas [4], Lei et al.[6], Kasai et al.[7], Mishra et al. [8], Cho et al.[9] apontam ainda que a região do menisco ondula e amplitude das ondas depende da velocidade de descarga de aço no molde e profundidade de imersão da SEN. Estes pesquisadores ressaltam ainda que o nível de turbulência na região do menisco decresce com o aumento da profundidade de imersão da SEN. Os vórtices são transientes e provocam a aprisionamento irregular de escória do molde nas imediações da SENe ainda que porções da escória do molde podem-se ser arrastada sobre a superfície da SEN até às portas da mesma, aumentando a contaminação da poça de aço no molde. Cho et al. [9] apontam ainda que o desalinhamento da SEN coopera no desenvolvimento de vórtices na região do menisco. E ainda que a formação de vórtices na região do menisco pode ser inibida por meio da otimização do projeto da SEN.

\section{CONCLUSÃO}

Os resultados obtidos mostram os efeitos da presença de escória no molde, profundidade de imersão da SEN e velocidade de lingotamento sobre as

* Contribuição técnica ao $45^{\circ}$ Seminário de Aciaria - Internacional, 25 a 28 de maio de 2014, Porto Alegre, RS, Brasil. 
distribuições horizontal e vertical de velocidades no líquido no interior de um molde de lingotamento contínuo de placas operando em regime de fluxo de duplo rolo. As regiões mais próximas à SEN são dotadas de maiores velocidades; por isso, são responsáveis pela formação de vórtices e contaminação na poça de aço. Não foi possível uma conclusão da influência da escória de topo na velocidade do fluxo. No estudo de diferentes imersões, observou-se que uma maior imersão da válvula acarreta maiores velocidades em determinadas regiões.

\section{Agradecimentos}

À FAPEMIG e ao CNPq pelo apoio financeiro à esta pesquisa.

\section{REFERÊNCIAS}

1 Liu R, Thomas BG, Sengupta J. Simulation of transient fluid flow in mold region during steel continuous casting, IOP Conf. Series. Materials Science and Engineering; 2012;33:1-11.

2 Yamashita S, Iguchi M. Mechanism of mold powder entrapment caused by large argon bubble in continuous casting mold. ISIJ International. 2001;41(12):1529-32.

3 Lu Q, Yang R, Wang X, Zhang J, Wang W. Water modeling of mold powder entrapment in slab continuous casting mold. Journal of University of Science and Technology Beijing, Mineral, Metallurgy, Material. 2007;14(5):399-404.

4 Hibbeler LC, Thomas BG. Investigation of mold flux entrainment in CC molds due to shear layer instability. Assoc. Iron Steel Technology ; 12nd Aug. 2010 ; Warrendale, EUA. CCC Report 201001; 2010. p.1-16.

5 Jabri K. Etude et amélioration des performances et de la robustesse des lois de commande de procédés sidérurgiques application à la régulation de niveau en coulée continue[tese de doutorado]. Orsay: Universidade Paris-Sul 11 ; 2010. p.226.

6 Lei Hong, Zhu Miao-Yong, He Ji-Cheng. Physical modeling of the Vortex phenomenon in continuous casting mould[J]. Chinese Journal of Process Engineering. 2001;1(1):36-39.

7 Kasai N, Iguchi M. Water-model experiment on melting powder trapping by vortex in the continuous casting mould. ISIJ International; 2007:47(7):982-87.

8 Mishra P, Ajmani SK, Kumar A, Shrivastava KK. Experimental investigation of SEN and mould for continuous slab caster by physical modelling. International Journal of Engineering Science and Technology (IJEST). 2012;4(6):2748-58.

9 Cho S-M, Lee G-G, Kim S-H, Chaudhary R, Kwon O-D, Thomas B.G. Effect of stopperrod misalignment on asymmetric flow and vortex formation in steel slab casting. In: TMS. JIM EVANS Honorary symposium; 2010. Warrendale: TMS; 2010. p.71-77.

Referência [1] não está citada no texto.

Verificar numeração e título de Figura 12 I Figura 13.

* Contribuição técnica ao 45 Seminário de Aciaria - Internacional, 25 a 28 de maio de 2014, Porto Alegre, RS, Brasil. 